Enfermagem Brasil 2016;15(6):301-6

\title{
ARTIGO ORIGINAL \\ Banho com e sem antimicrobiano: estudo realizado em neonato de risco
}

Sara Rodrigues Ramalho*, Franciele do Prado Reis*, Leila Katiane da Cruz Dibbern**, Carla Regina Bianchi Codo***

${ }^{*}$ Graduanda em enfermagem e aluna de iniciação científica pela Faculdades Integradas Einstein de Limeira (FIEL), ${ }^{* *}$ Docente do curso de biomedicina da FIEL, ${ }^{* * *}$ Orientadora e docente do curso de Enfermagem da FIEL, Doutoranda em Ciências médicas pela Faculdade de Ciências Médicas da Universidade Estadual de Campinas - Unicamp

Recebido em 18 de outubro de 2016; aceito em 26 de dezembro de 2016.

Endereço para correspondência: Sara Rodrigues Ramalho, Rua Jatobá, 200, Vila Queiroz, 13485-023 Limeira SP, E-mail: sararramalho@hotmail.com, carlacodo@yahoo.com.br

\section{Resumo}

Introdução: $\mathrm{Na}$ atualidade existe uma grande preocupação da equipe das unidades neonatais com os cuidados com a pele do neonato prematuro. Muitas vezes as unidades de saúde usam cuidados empíricos no cuidado com a pele dos mesmos, principalmente com relação ao banho. Objetivo: Avaliar e comparar a influência do banho com água e do banho com clorohexidina sobre a flora bacteriana nosocomial da pele do RNPT antes e após a execução do mesmo. Métodos: Quantitativo, prospectivo, randômico, experimental, de caso coorte cego para atingir o objetivo proposto. Ao nascimento o neonato foi sorteado recebendo um número que 0 identificava de acordo com o tipo de banho a ser executado, sendo (A) banho com água e (C) banho com clorohexidina a $2 \%$. Resultados: Para o banho com clorohexidina a $2 \%$ dos onze sujeitos, quatro apresentaram presença de microrganismos. Quanto ao banho com água, no qual se obteve doze sujeitos, sete apresentaram resultados positivos para microrganismos. Conclusão: Após a execução dos banhos de acordo com a metodologia estabelecida neste estudo, observou-se que tanto o banho com clorohexidina a $2 \%$, como o banho somente com água, são efetivos na remoção de microrganismos da pele dos recém-nascidos pré-termo.

Palavras-chave: pré-termo, banho, emolientes.

\begin{abstract}
Bath with and without antimicrobial: study of neonates at risk

Introduction: Nowadays there is a great concern of the neonatal intensive care unit staff with skin care of the premature neonate baby (PTNB). Health care units often use empirical care in babies skin care, especially with respect to bath. Objective: To evaluate and compare the influence of the bath with water and bath with chlorhexidine on nosocomial bacterial flora of PTNB skin before and after implementation. Methods: Quantitative, prospective, randomized, experimental, blind cohorte case to achieve the objective. At birth the infant was randomized receiving a number that identified according to the type of bath to be executed: $(A)$ with water and $(\mathrm{C})$ with $2 \%$ chlorhexidine. Results: We found that four out of eleven infants who used chlorhexidine $2 \%$ showed the existence of microorganisms. As per the bath water, seven out of twelve subjects were positive for microorganisms. Conclusion: After the execution of the baths according to the methodology set out in this study, it was observed that both the bath with chlorhexidine $2 \%$ as well as the bath only with water is effective in removing microorganisms of preterm newborn skin.
\end{abstract}

Key-words: preterm, bath, emollients.

\section{Resumen}

Baño con y sin antimicrobiano: estudio realizado en neonato de riesgo

Introducción: En la actualidad existe una gran preocupación del personal de las unidades neonatología con el cuidado de la piel del recién nacido prematuro (RNPT). A menudo, las unidades de cuidados de la salud se valen de cuidados empíricos, especialmente en el momento del baño. Objetivo: Evaluar y comparar la influencia del baño con agua y baño con clorhexidina sobre la flora bacteriana nosocomial de la piel del RNPT antes y después de la ejecución del mismo. Métodos: Cuantitativo, prospectivo, aleatorio, experimental, de caso coorte ciego para lograr el objetivo propuesto. Al nacer los bebés fueron sorteados y recibieron 
un número que los identificaba de acuerdo con el tipo de baño: $(A)$ baño con agua y $(C)$ baño con clorohexidina a $2 \%$. Resultados: Para el baño con clorohex a $2 \%$, de los once niños, cuatro presentaron resultados positivos para microorganismos. En cuanto al baño con agua, en el cual fueron sorteados doce recién nacidos, siete presentaron resultados positivos para microorganismos. Conclusión: Después de la ejecución de los baños de acuerdo con la metodología establecida en este estudio, se observa que tanto el baño con clorohexidina a $2 \%$ como el baño solamente con agua son efectivos en la remoción de microorganismos de la piel de los recién nacidos pretérminos.

Palabras-clave: prematuro, baño, emolientes.

Introducão

A sobrevida dos neonatos de risco tem aumentado na atualidade em decorrência da evolução do cuidado e das técnicas empregadas ao cuidado do mesmo [1-3]. Entre estas está a preocupação com relação a pele do neonato e a manutenção da integridade da mesma; pois, segundo Darmstadt et al. [4], lesões ou alterações do seu pH contribuem para o aparecimento de infecções, aumentando o risco de morbidade e mortalidade desta classe de pacientes. Segundo muitas unidades, baseadas em conhecimento empírico, a prática do banho aumenta o dano tecidual, propiciando ao RNPT uma maior propensão a desenvolver processos infecciosos.

Ao nascimento, a pele do RN sofre a sua primeira colonização e com uma semana de vida encontra-se semelhante à observada no adulto. Entretanto, o sistema imunológico deste órgão só irá funcionar plenamente aos nove meses de vida. Isto explica a maior suscetibilidade dos prematuros em desenvolver processos infecciosos [5,6].

O mecanismo que auxilia a eliminação das bactérias é a formação do manto ácido da pele. Nos prematuros esta acidez é fraca, podendo-se encontrar pH básico na axila, pescoço e coxa [5-7]; o que demonstra a maior sensibilidade destas áreas a desenvolver agravos como as dermatites de contato. Hahn [7] relata que a pele do RNPT sofre maturação entre a segunda e a quarta semana de vida pós-uterina, e que prematuros extremos podem levar até oito semanas para completar a formação do extrato córneo. Pode-se verificar, portanto, que a pele do RNPT tem características e funções próprias inerentes de um indivíduo em formação, e que cuidados dispensados a estes neonatos podem alterar a função da pele com relação à barreira e perda transepidérmica de água. Cabe ao profissional que trabalha em unidades neonatais, estar atento aos detalhes inerentes à pele do prematuro, para que se possa escolher o melhor tipo de cuidado a ser realizado.

O banho merece ser avaliado, pois pode causar alterações na pele como irritação e traumas, hipotermia, aumento do $\mathrm{pH}$ - em decorrência do tipo de sabão utilizado na higienização - reduzindo o fator de proteção da mesma, como também acarretar aumento do consumo de oxigênio e alterações dos sinais vitais [7]. A pele do recém-nascido difere de um para outro conforme a idade gestacional. É o maior órgão do corpo humano e suas funções vão desde a proteção, regulação térmica e hidroeletrolítica até a recepção de impulsos táteis como o toque, a temperatura, a dor e a pressão [8].

Acreditava-se, até algum tempo atrás, que a função de barreira cutânea atingia sua maturidade por volta da $34^{\text {a }}$ semana de gestação. Contudo, dados recentes mostram que ela continua a se desenvolver até 12 meses após o nascimento. A pele do neonato é submetida a um progressivo processo de adaptação ao ambiente extrauterino, para o qual cuidados especiais se tornam necessários [8].

\section{Objetivo}

Avaliar e comparar a influência do banho com água e do banho com clorohexidina sobre a flora bacteriana nosocomial da pele do RNPT antes e após a execução do mesmo.

\section{Material e métodos}

A metodologia utilizada foi quantitativa prospectiva, randômica, experimental, de caso coorte cego, buscando descrever a interferência do banho com clorohex e somente com água sobre o desenvolvimento de bactérias na pele do neonato prematuro. Teve ainda a finalidade comparativa, determinando o tipo de flora nosocomial na pele do neonato pré-termo de acordo com o tipo de banho ao qual foi submetido por múltiplos períodos de coleta de dados $[9,10]$. 
Fizeram parte deste estudo os prematuros que nasceram com peso entre 500 a $2500 \mathrm{~g}$, de qualquer idade gestacional, cujos pais/responsável assinaram o termo de consentimento livre e esclarecido. Foram excluídos todos os neonatos que apresentaram infecção ovular, pela necessidade de antibióticoterapia; ou que tenham nascido com SAM (síndrome da aspiração de mecônio), pois estas patologias indicam necessidade de banho logo após o nascimento, fato este que prejudicaria a coleta de dados de modo fidedigno. Tamanho da amostra foi determinado com base em trabalho já realizado [11], sendo de 20 neonatos para cada tipo de banho, já com a margem de segurança e um poder de teste de $80 \%$.

Os neonatos foram sorteados da seguinte forma: o primeiro neonato que nasceu foi sorteado dentro dos dois grupos de pesquisa estabelecidos, ou seja, A ou C; o segundo recebeu o grupo que ficou faltando e o terceiro foi sorteado novamente entre os dois grupos e assim sucessivamente. Recebendo denominação de grupo C: banho com clorohex; grupo A: banho somente com água. Os neonatos foram denominados em ordem numérica em tabela paralela permitindo identificar o tipo de microrganismo de acordo com o tipo de banho a que foram submetidos. Para verificar o tipo de microrganismos foi colhido um swab na axila D, perfazendo cinco (5) movimentos na horizontal e cinco (5) movimentos na vertical, em um espaço correspondente a $1 \mathrm{~cm}^{2}$, com base em trabalho desenvolvido por Cunha e Procianoy [11]. Os swabs colhidos foram encaminhados ao laboratório das Faculdades Einstein de Limeira, semeados em placa ágar chocolate e colocados em estufa, com leitura posterior a 48 horas. Foi identificado o tipo de microrganismo presente de acordo com cada tipo de banho. Portanto cada neonato foi submetido a duas coletas; uma antes da execução do banho para identificar os microrganismos primários e outra depois de cinco dias de execução da técnica de banho. Este tempo de espera se justifica devido ao desenvolvimento bacteriano ocorrer na pele, ou seja, a sua colonização ocorrer na primeira semana de vida no prematuro $[5,6]$.

O banho foi realizado utilizando-se uma pequena banheira de plástico, previamente limpa com álcool a 70\%. Ou foi utilizado banho com gaze; algodão e cuba rim. O banho somente foi realizado após condições clínicas estáveis do neonato na unidade intensiva neonatal da ISCM de Limeira, hospital privado, filantrópico de nível terciário. A população também foi caracterizada quanto ao sexo; idade gestacional; peso de nascimento e hipótese diagnóstica. Não houve necessidade de realizar o acompanhamento dos sujeitos, 0 procedimento do banho já é uma técnica de enfermagem realizada dentro do ambiente das UTINs.

O trabalho foi aprovado pelo comitê de ética da plataforma Brasil com CAAE sob o número 36690814.5.0000.5608. Todos os sujeitos participantes assinaram o termo de consentimento livre e esclarecido.

Resultados

Para a análise estatística, utilizou-se o programa Biostat 5.3. Como os resultados obtidos deram negativo ou positivo para bactéria e os programas aceitam dados numéricos, estabeleceu-se o valor numérico 1 para os banhos nos quais não houve crescimento de microrganismo e 2 para os banhos nos quais foi identificado presença dos mesmos.

$\mathrm{Na}$ comparação antes e depois do banho com clorohexidina a $2 \%$, verificou-se que antes do banho, oito neonatos apresentaram resultados negativos para microrganismos e três positivos; após, sete continuaram negativos para microrganismos e quatro positivos. Como a amostra é pareada, foi utilizado o teste de McNemar com um (p) valor de 1,000, que significa que não houve diferença estatisticamente significativa da presença de microrganismos antes e após o banho com emolientes (Tabela I).

Tabela I - Presença de microrganismos antes e após o banho com emoliente clorohexidina.

\begin{tabular}{llll}
\hline Sujeitos & $\begin{array}{l}\text { Ausência de } \\
\text { microrganismo }\end{array}$ & $\begin{array}{l}\text { Presença de } \\
\text { microrgan ismo }\end{array}$ & P valor \\
\hline C antes $(11)$ & $08(72,7 \%)$ & $03(27,3 \%)$ & $\mathrm{P}=1,0000$ \\
$\mathrm{C}$ depois $(11)$ & $07(63,6 \%)$ & $04(36,4 \%)$ & $\mathrm{P}=1,0000$ \\
\hline
\end{tabular}

Para o banho com água, obteve-se os seguintes resultados: sete neonatos não apresentaram microrganismo identificado antes do banho, enquanto cinco apresentaram microrganismo antes do banho. Após cinco dias do banho somente com água, cinco neonatos estavam negativos para a presença de microrganismos e sete deram positivos para bactérias. 
O teste utilizado foi o McNemar com um (p) valor de 0,625 , o que indica que não houve diferença estatisticamente significativa no desenvolvimento de microrganismos com a utilização de água somente - antes e após o banho. Para esta análise, as amostras também são pareadas (Tabela II).

Tabela II - Presença de microrganismos antes e após o banho com água.

\begin{tabular}{llll}
\hline Sujeitos & $\begin{array}{l}\text { Ausência de } \\
\text { microrganismo }\end{array}$ & $\begin{array}{l}\text { Presençade } \\
\text { microrganismo }\end{array}$ & P valor \\
\hline A antes (12) & $07(58,3 \%)$ & $05(41,7 \%)$ & $\mathrm{P}=0,625$ \\
A depois (12) & $05(41,7 \%)$ & $07(58,3 \%)$ & $\mathrm{P}=0,625$ \\
\hline
\end{tabular}

Para o banho com clorohex a $2 \%$, dos onze sujeitos, quatro apresentaram presença de microrganismos. Para o banho com água, no qual se obteve doze sujeitos, sete deram positivos para microrganismos. Para a comparação destas amostras, utilizou-se o teste de Fisher para amostras não pareadas com um (p) valor de 0,414 , que indica que não houve diferença estatisticamente significativa entre os dois tipos de banho, ou seja, tanto o banho com clorohex como o banho com água são efetivos na remoção de microrganismos (Tabela III).

Tabela III - Comparação do desenvolvimento de flora nosocomial na pele do prematuro após a execução de dois tipos de banho.

\begin{tabular}{llll}
\hline Sujeitos & $\begin{array}{l}\text { Ausência de } \\
\text { microrganismo }\end{array}$ & $\begin{array}{l}\text { Presença de } \\
\text { microrganismo }\end{array}$ & P valor \\
\hline C depois (11) & $07(55,6 \%)$ & $04(44,4 \%)$ & $\mathrm{P}=0,414$ \\
A depois (12) & $05(41,7 \%)$ & $07(58,3 \%)$ & $\mathrm{P}=0,414$ \\
\hline
\end{tabular}

Esta pouca diferença pode ter ocorrido pela perda de uma grande quantidade de amostra entre os dois tipos de banho e pela resistência da equipe da instituição em estar auxiliando a execução do estudo.

A coleta foi realizada até o número total de sujeitos alcançar os vinte banhos para cada tipo. Entretanto, dos neonatos participantes do estudo para o banho com clorohexidina a $2 \%$, três foram a óbito antes da segunda coleta; seis foram transferidos para a maternidade e receberam outro tipo de banho, inviabilizando a segunda coleta, perfazendo o total de 11 sujeitos. Para o banho com água, dois neonatos foram a óbito e seis foram perdidos por transferência, resultando em um total de 12 sujeitos. A coleta foi realizada de setembro de 2015 a março de 2016.

\section{Discussão}

Pode-se constatar que tanto o banho com emoliente clorohexidina como o banho com água foram efetivos na remoção de microrganismos da pele do neonato. Isto também foi encontrado no trabalho de Cunha e Procianoy [11], entretanto, no estudo destes autores, os neonatos já haviam sido submetidos à execução do banho de rotina da unidade, o que poderia acarretar um viés no estudo. $O$ atual não houve banho antes da primeira coleta, entretanto os resultados foram semelhantes. Cabe aqui ressaltar que a utilização da clorohexidina é usada no local em que ocorreu o estudo desde 1996, sem que com isto ocasionasse qualquer tipo de lesão de pele ou intoxicação considerando-se que no trabalho citado anteriormente não se estudou o efeito no desenvolvimento da pele do pré-termo.

Houve muita dificuldade em se obter artigos científicos para embasamento, pois apesar dos avanços técnicos na área da neonatologia, certos procedimentos ainda se baseiam no campo empírico, determinando uma rotina de cuidados, sem estudos aprofundados nessa temática, com prática baseada em evidência, que muitas vezes é uma exceção ao que se observa na rotina. Não há na literatura, estudos que comprovem a interferência do banho, no recém-nascido pré-termo. Estudos reconhecem o efeito do clorohex no bebê a termo, seu efeito residual e também a influência do banho, somente com água e com emoliente comum na flora do prematuro.

Encontra-se na literatura diversas indicações de produtos que devem ser utilizados no banho e no cuidado com a pele do prematuro como água estéril morna [6], sabonete neutro [12], clorohexidina a $2 \%$ e óleos a base de petrolato e lanolina [7]. $O$ uso de sabão no banho 
pode provocar uma incidência elevada de lesões de pele [6]. Entretanto, o uso de sabonetes a base de clorohexidina a $2 \%$ ainda não foram estudados, tanto quanto a sua eficácia na proteção do neonato, quanto na probabilidade de provocar lesões de pele e sobre a sua toxicidade.

Tapla e Martins [13] referem que a pele do prematuro funciona como tegumento de barreira contra infecções, sendo a primeira linha de defesa.

A utilização de clorohexidina tem provocado uma boa redução no número de bactérias como o Staphylococcus áureus por um período de até 4 horas [7]. Ercan, Dalli e Düigergil [14] também concluíram que este tipo de substância tem sido mais eficiente em eliminar Enterococcus e Cândida albicans e afirmam em seu trabalho que mais estudos devem ser formulados a respeito do uso desta substância.

Ainda em seu estudo, Hahn [7] relata que a utilização de água estéril morna é recomendada para evitar a alteração da flora bacteriana da pele, mas os dados apresentados neste estudo demonstram que mesmo a água altera a mesma.

Conclusão

Pode-se verificar que na literatura existem muitas informações conflitantes em relação aos cuidados durante o banho e com a pele do neonato prematuro, fazendo com que os profissionais tenham uma dificuldade em relação ao uso ou não de emolientes.

Infelizmente vários percalços na coleta de dados inviabilizaram que a totalidade de sujeitos escolhidos tivessem seus resultados apresentados neste estudo. $O$ total de sujeitos obtidos no final para os dois tipos de banho pode ter sido insuficiente para determinar com exatidão uma comparação entre os dois tipos de banho. Talvez se a totalidade de sujeitos tivesse sido alcançada os resultados pudessem ser diferentes. Ocorreu muita dificuldade por parte da equipe de assistência dentro da unidade que prejudicou a execução do estudo.

O que se pôde observar é que tanto para o banho com emoliente clorohexidina como para o banho com água ocorreu redução do número de microrganismos. Entretanto, pelas dificuldades encontradas, recomenda-se um olhar mais crítico e uma avaliação mais cautelosa sobre a execução do banho nos recém-nascidos pré-termo comparando o uso de emolientes na execução do mesmo.

Agradecimentos

Projeto financiado pelo PAPIC da Faculdades Integradas Einstein de Limeira - FIEL

1. Scocchi CGS. A humanização da assistência hospitalar ao bebê prematuro, bases teóricas para o cuidado de enfermagem [Tese]. Ribeirão Preto: Escola de Enfermagem de Ribeirão Preto, USP; 2000. 245p.

2. Margotto PR. Recém-nascido pré-termo extremo, limite de viabilidade. [citado 2006 Ago 23]. Disponível em URL: http://www.medigo.org.br

3. Rolim KMC, Cardoso MVLML. O discurso e a prática do cuidado ao recém-nascido de risco, refletindo sobre a atenção humanizada. Rev Latinoam Enferm 2006;14(1):85-92.

4. Darmstadt GL, Saha SK, Ahmed AS, Chowdhury MA, Law PA, Ahmed S et al. Effect of topical treatment with skin barrier-enhancing emollients on nosocomial infections in preterm infants in Bangladesh: a randomized controlled trial. Lancet 2005;365(9464):1039-45.

5. Belilovsky C. A pele do recém-nascido. 2001. S/volume e número. [citado 2008 Ago 23]. Disponível em URL: http://wwwmustela.com

6. Cunha MLC, Mendes ENW, Bonilha ALDL. O cuidado com a pele do recém-nascido. Rev Gaúcha Enferm 2002;23(2):6-15.

7. Hahn LP. Pele do recém-nascido prematuro. 2001. [Monografia]. Universidade Federal do Paraná: Departamento de pediatria do Hospital das Clínicas. [citado 2010 Mar 20]. Disponível em URL: http://www.hc.ufpr.br/acad/pediatria

8. Fernandes JD, Machado MCR, Oliveira ZNP. Prevenção e cuidados com a pele da criança e do recém-nascido. An Bras Dematol 2011;86(1) 
9. Polit DF, Beck CT, Hungler BP. Fundamentos de pesquisa em enfermagem, métodos, avaliação e utilização. Traduzido por Ana Thorell. 5ª ed. Porto Alegre: Artmed; 2004.

10. Hulley SB, Cummings SR, Browner WS, Grady D, Herars TN, Newman TB. Delineando a pesquisa clínica, uma abordagem epidemiológica. $2^{\underline{a}}$ ed. Porto Alegre: Artmed; 2003.

11. Cunha MLC, Procianoy RS. Effect of bathing on skin flora of preterm newborns. J Perinatol 2005;25(6):375-9.

12. Brasil. Ministério da Saúde. Atenção humanizada ao recém-nascido de baixo peso, método mãe canguru. Brasília: Ministério da Saúde; 2002.

13. Martins CP, Tapla CEV. A pele do recém-nascido prematuro sob a avaliação do enfermeiro, cuidado norteando a manutenção da integridade cutânea. REBEN 2009;62(5):778-83.

14. Ercan E, Dalli M, Dülgergil CT. In vitro assessment of the effectiveness of chlorhexidine gel and calcium hydroxide paste with chlorhexidine against Enterococcus faecalis and Candida albicans. Oral Surg Oral Med Oral Pathol Oral Radiol Endod 2006;102(2):e2731. 